\title{
A study of surface roughness in drilling using mathematical analysis and neural networks
}

\author{
C. Sanjay $\cdot$ C. Jyothi $\cdot$ C. W. Chin
}

Published online: 19 August 2006

(C) Springer-Verlag London Limited 2006

The online version of the original article can be found at: http://dx.doi. org/10.1007/s00170-005-2538-8.

C. Sanjay $(\bowtie)$

Faculty of Manufacturing Engineering, KUTKM,

1200 Ayer keroh, locked bag,

Melaka 75450, Malaysia

e-mail: sasch_cheen@yahoo.com

C. Jyothi

Tata Indiacom,

Hyderabad, India

C. W. Chin

Multimedia University, Faculty of Engineering and Technology,

Jalan Ayer Keroh,

Melaka 75450, Malaysia

e-mail: cwchin@mmu.edu.my
Due to an unfortunate error one author was omitted. We regret this error and provide herewith the complete information. 